Article

\title{
Cost and Ductility Effectiveness of Concrete Columns Strengthened with CFRP and SFRP Sheets
}

\section{Khaled Abdelrahman and Raafat El-Hacha *}

Department of Civil Engineering, University of Calgary, 2500 University Drive N.W., Calgary, Alberta T2N 1N4, Canada; E-Mail: kabdelra@ucalgary.ca

* Author to whom correspondence should be addressed; E-Mail: relhacha@ucalgary.ca; Tel.: +1-403-220-4817; Fax: +1-403-282-7026.

Received: 26 December 2013; in revised form: 19 April 2014 / Accepted: 4 May 2014 /

Published: 13 May 2014

\begin{abstract}
Recently, steel fibre reinforced polymers (SFRP) sheets have been introduced for the repair and rehabilitation of concrete structures. Few researchers studied the behaviour of the concrete columns wrapped with SFRP sheets; however, several critical parameters such as the cost and ductility effectiveness of the SFRP wrapped concrete columns have been lightly addressed. Thus, the main objective of this paper is to study the cost and ductility effectiveness of SFRP wrapped concrete columns and compare the results with the conventionally used carbon FRP (CFRP) wrapped concrete columns. In addition, an analytical procedure to predict the cost effectiveness of SFRP wrapped concrete columns is also suggested, from which, a parametric study was conducted. The parametric study investigated the effect of the concrete strength, the number of SFRP layers, and the size and slenderness effects on the cost effectiveness of the concrete columns wrapped with SFRP sheets. The results from the cost and ductility effectiveness study indicated that the SFRP wrapped concrete columns showed enhanced performance over the CFRP wrapped concrete columns. The suggested analytical procedure proved to be a reliable and accurate method to predict the cost effectiveness parameter of SFRP wrapped concrete columns. The parametric study showed the significant impact of the investigated parameters on the cost effectiveness of concrete columns wrapped with SFRP sheets.
\end{abstract}

Keywords: axial; carbon; circular; cost; confinement; ductility; effectiveness; sheet; steel fiber reinforced polymer; strength 


\section{Introduction}

Strengthening of reinforced concrete (RC) columns using fibre reinforced polymers (FRP) is one of the very efficient methods to enhance the strength and ductility of the concrete. The FRP types commonly used for confinement applications are carbon FRP (CFRP), glass FRP (GFRP), aramid FRP (AFRP), and steel FRP (SFRP). There is an ample amount of information available in the literature concerning the behaviour of RC columns wrapped with CFRP, GFRP and AFRP sheet (a few are listed: [1-14]). However, only recently, SFRP sheets have attracted researchers' interest for confinement applications due to the significant enhancement it offers to the RC columns compared to the conventional FRP sheets [15-19].

Based on experimental data and research, the behaviour of SFRP wrapped concrete columns subjected to normal room temperature, freeze-thaw, humidity and prolonged high temperature was superior to columns wrapped with the conventionally used CFRP sheets [20-22]. Yet, the cost and ductility effectiveness parameters are other criteria required to evaluate the effectiveness of the SFRP sheets for confinement applications. Thus, in this paper, the cost and ductility effectiveness parameters of SFRP and CFRP wrapped concrete columns are evaluated and compared.

Limited information on design procedures related to SFRP wrapped concrete columns is available in the literature [23]. During the design process, cost effectiveness is one of the crucial factors in determining the type of the strengthening material required to enhance the behaviour of the concrete column. Thus, an analytical procedure to predict the cost effectiveness of the SFRP sheets is necessary. Recently, Abdelrahman and El-Hacha [23] proposed an equation to predict the ultimate strength of concrete columns wrapped with SFRP sheets. The proposed equation showed accurate predictions of the SFRP confined concrete strength, when compared to the experimental data [23]. In this paper, the proposed equation has been incorporated into an analytical procedure to predict the cost effectiveness of SFRP wrapped concrete columns. The predicted cost effectiveness results shall be validated with the experimental data. Once validated, a parametric study on the cost effectiveness is performed, where the variables investigated were the concrete strength, number of SFRP layers, slenderness and size effects.

\section{Experimental Program}

The experimental program was divided into two categories of columns, the first category was designed to investigate the cost and ductility effectiveness of large-scale concrete columns, and the second category was designed to investigate the cost effectiveness of concrete columns with varying slenderness ratio. The first category consisted of 18-large scale concrete columns with dimensions of $300 \mathrm{~mm}$ in diameter and $1200 \mathrm{~mm}$ in height. The columns were divided into five groups (A, B, C, $\mathrm{D}$, and $\mathrm{E}$ ), which varied according to the column type (unwrapped, CFRP wrapped columns and SFRP wrapped columns), column longitudinal reinforcement ratio (non-reinforced and reinforced), environmental exposure conditions (room temperature of $+22{ }^{\circ} \mathrm{C}$ and freeze-thaw cycling of $+34{ }^{\circ} \mathrm{C}$ to $-34^{\circ} \mathrm{C}$ ) and the fibre orientation of the FRP sheet (circumferential: $0^{\circ}$ and longitudinal/circumferential: $90^{\circ} / 0^{\circ}$ ). The addition of an inner longitudinal FRP layer was to investigate the durability performance of the concrete. Also, the inner longitudinal FRP layer was intended to regulate the crack distribution and reduce the stress concentration on the outer circumferential FRP layer to increase the strain 
efficiency of the FRP sheet. A summary of the test matrix of the large-scale columns in the first category is provided in Table 1.

Table 1. Test matrix of the large-scale columns wrapped with CFRP and SFRP sheets, with their respective control specimens.

\begin{tabular}{ccccc}
\hline Group & FRP Type & FRP Orientation * & Exposure & Column ID \\
\hline \multirow{4}{*}{ A } & Unwrapped & - & $22{ }^{\circ} \mathrm{C}$ & NR-CT-RT \\
& CFRP & $0^{\circ}$ & $22{ }^{\circ} \mathrm{C}$ & NR-CFRP-RT \\
& SFRP & $0^{\circ}$ & $22{ }^{\circ} \mathrm{C}$ & NR-SFRP-RT \\
B & Unwrapped & - & -34 to $+34{ }^{\circ} \mathrm{C}$ & NR-CT-EE \\
& CFRP & $0^{\circ}$ & -34 to $+34{ }^{\circ} \mathrm{C}$ & NR-CFRP-EE \\
& SFRP & $0^{\circ}$ & -34 to $+34{ }^{\circ} \mathrm{C}$ & NR-SFRP-EE \\
& Unwrapped & - & $22{ }^{\circ} \mathrm{C}$ & R-CT-RT \\
C & CFRP & $0^{\circ}$ & $22{ }^{\circ} \mathrm{C}$ & R-CFRP-RT \\
& CFRP & $90^{\circ} / 0^{\circ}$ & $22{ }^{\circ} \mathrm{C}$ & R-CFRP-HV-RT \\
& SFRP & $0^{\circ}$ & $22{ }^{\circ} \mathrm{C}$ & R-SFRP-RT \\
& SFRP & $90^{\circ} / 0^{\circ}$ & $22{ }^{\circ} \mathrm{C}$ & R-SFRP-HV-RT \\
& Unwrapped & - & -34 to $+34{ }^{\circ} \mathrm{C}$ & R-CT-EE \\
& CFRP & $0^{\circ}$ & -34 to $+34{ }^{\circ} \mathrm{C}$ & R-CFRP-EE \\
D & CFRP & $90^{\circ} / 0^{\circ}$ & -34 to $+34{ }^{\circ} \mathrm{C}$ & R-CFRP-HV-EE \\
& SFRP & $0^{\circ}$ & -34 to $+34{ }^{\circ} \mathrm{C}$ & R-SFRP-EE \\
& SFRP & $90^{\circ} / 0^{\circ}$ & -34 to $+34{ }^{\circ} \mathrm{C}$ & R-SFRP-HV-EE \\
& CFRP & $0^{\circ}$ & -34 to $+34{ }^{\circ} \mathrm{C}$ & R-CFRP-AEE \\
E & SFRP & $0^{\circ}$ & -34 to $+34{ }^{\circ} \mathrm{C}$ & R-SFRP-AEE \\
\hline
\end{tabular}

$* 0^{\circ}$ : fibres oriented in the hoop direction; $90^{\circ}$ : fibres oriented in the longitudinal direction.

The specimen ID shown in Table 1 can be described as follows: the first/second letter designates the research group ("R" refers to reinforced and "NR" refers to non-reinforced columns), followed by the letters representing the wrapping material ("CT" for control unwrapped specimens, "CFRP" for CFRP wrapped sheets, and "SFRP" for SFRP wrapped sheets). In some cases, the third letter indicates the fibre orientation $\left(0^{\circ}\right.$ for the circumferential direction and $90^{\circ}$ for the longitudinal direction), where "HV" refers to columns strengthened horizontally and vertically, and the last letter refers to the type of exposure ("RT" for room temperature, "EE" for environmental exposure conditions before FRP wrapping and "AEE" for the columns wrapped after environmental exposure).

The second category of columns consisted of 34-circular unreinforced concrete specimens each measuring $150 \mathrm{~mm}$ in diameter with varying heights of 300, 600 and $900 \mathrm{~mm}$. The dimensions of the specimens were selected in order to obtain aspect ratios $(H / D$, where $H$ and $D$ refer to the height and the diameter of the specimen, respectively) of 2, 4 and 6. Each group of aspect ratio contained six specimens; three were left unwrapped to act as control specimens and three were wrapped with one layer of CFRP or SFRP sheets, with the exception of the control column with aspect ratio of 4 in the CFRP group, where only one specimen was tested. It should be noted that the authors only tested the aspect ratio columns wrapped with SFRP sheets, with their respective control specimens (Table 2). However, the columns wrapped with CFRP sheets along with their control specimens were tested by Bisby and Stratford [24]. The experimental program adopted in their study used a similar CFRP type 
for confining the aspect ratios columns as the CFRP type used in this investigation for confining the large-scale columns in the first category. Their investigation also included similar aspect ratios, columns dimensions, and the number of specimen repetitions (Table 3). However, the column ID was altered to be consistent with the labeling system used in this research.

The specimen ID shown in Tables 2 and 3 can be described as follows: the first letter designates the research group ("AR" refers to aspect ratio columns), followed by the number representing the category of the aspect ratio specimens $(2,4$, and 6$)$, followed by the letters representing the specimen type ("CT" for control specimens, "CFRP" for CFRP wrapped specimens and "SFRP" for SFRP wrapped specimens), and the last digit (1,2 or 3$)$ indicates the specimen number for the same group to verify repeatability of the results.

Table 2. Test matrix of the aspect ratio columns wrapped with SFRP sheets, along with their respective control specimens.

\begin{tabular}{cccccc}
\hline $\begin{array}{c}\text { Aspect Ratio } \\
(\boldsymbol{H} / \boldsymbol{D})\end{array}$ & $\begin{array}{c}\text { Diameter, } \boldsymbol{D} \\
(\mathbf{m m})\end{array}$ & $\begin{array}{c}\text { Height, } \boldsymbol{H} \\
(\mathbf{m m})\end{array}$ & FRP Type & $\begin{array}{c}\text { Number of } \\
\text { Specimens }\end{array}$ & Column ID \\
\hline \multirow{2}{*}{2} & \multirow{2}{*}{150} & 300 & Unwrapped & 3 & AR-2-CT-(1/2/3) \\
& & & SFRP & 3 & AR-2-SFRP-(1/2/3) \\
4 & \multirow{2}{*}{150} & \multirow{2}{*}{600} & Unwrapped & 3 & AR-4-CT-(1/2/3) \\
& \multirow{2}{*}{150} & \multirow{2}{*}{900} & SFRP & 3 & AR-4-SFRP-(1/2/3) \\
& & & SFrapped & 3 & AR-6-CT-(1/2/3) \\
& & & & 3 & AR-6-SFRP-(1/2/3) \\
\hline
\end{tabular}

Table 3. Test matrix of the aspect ratio columns wrapped with CFRP sheets, along with their respective control specimens [24].

\begin{tabular}{cccccc}
\hline $\begin{array}{c}\text { Aspect Ratio } \\
(\boldsymbol{H} / \boldsymbol{D})\end{array}$ & $\begin{array}{c}\text { Diameter, } \boldsymbol{D} \\
(\mathbf{m m})\end{array}$ & $\begin{array}{c}\text { Height, } \boldsymbol{H} \\
(\mathbf{m m})\end{array}$ & FRP Type & $\begin{array}{c}\text { Number of } \\
\text { Specimens }\end{array}$ & Column ID \\
\hline \multirow{2}{*}{2} & \multirow{2}{*}{150} & 300 & Unwrapped & 3 & AR-2-CT-(1/2/3) \\
& & & CFRP & 3 & AR-2-CFRP-(1/2/3) \\
4 & \multirow{2}{*}{600} & Unwrapped & 1 & AR-4-CT-(1/2/3) \\
& \multirow{2}{*}{150} & & CFRP & 3 & AR-4-CFRP-(1/2/3) \\
6 & \multirow{2}{*}{150} & 900 & Unwrapped & 3 & AR-6-CT-(1/2/3) \\
& & & CFRP & 3 & AR-6-CFRP-(1/2/3) \\
\hline
\end{tabular}

It is important to note that the columns were wrapped such that the stiffness in the fibre direction of the SFRP and the CFRP wrapped concrete columns were similar for comparison purposes. Wrapping the concrete columns with one layer of SFRP sheet has almost an equivalent stiffness to the columns wrapped with one layer of the CFRP sheet (the stiffness $E A_{\mathrm{CFRP}}=24.92 \mathrm{MN}$ and $E A_{\mathrm{SFRP}}=25.05 \mathrm{MN}$, where $E$ is the modulus of elasticity of the FRP sheets and $A$ is the area/one meter of width). The experimental program was designed to study the effect of the longitudinal steel reinforcement, environmental exposure, the fibre orientation of the FRP sheet, size and slenderness effects. The type of the CFRP sheet used was unidirectional carbon fiber fabric with a thickness of $0.381 \mathrm{~mm}$. According to the manufacturer, the ultimate tensile strength, modulus of elasticity and strain at failure are $894 \mathrm{MPa}, 65,402 \mathrm{MPa}$ and $1.33 \%$, respectively [25]. The type of SFRP sheet used was $3 \times 2-20-12$ 
made from unidirectional brass coated ultra-high strength twisted steel wires with a thickness of $1.23 \mathrm{~mm}$ and net cross-sectional area of $0.38 \mathrm{~mm}^{2} / \mathrm{mm}$. The first two digits $(3 \times 2)$ indicate the hardwire cord type. The $3 \times 2$ cord is made by twisting 5 individual wire filaments together -3 straight filaments wrapped by 2 filaments. The third digit (20) indicates the tape density, in this case 20 WPI (wires per inch). The final digit (12) indicates the width of the sheet; in this case, the sheets were shipped in a 12 inch $(305 \mathrm{~mm})$ width. According to the manufacturer, the ultimate tensile strength, modulus of elasticity and strain at failure are $986 \mathrm{MPa}, 66,100 \mathrm{MPa}$, and 1.5\%, respectively [26]. Further information about the geometric and material properties of this study can be found in Abdelrahman [21] and Bisby and Stratford [24].

\section{Cost Effectiveness}

One of the methods to evaluate the effectiveness of the FRP sheet is to consider the cost effectiveness parameter. The cost effectiveness parameter is a function of the strength gain relative to the total cost associated with the construction and the FRP wrapping of the concrete column. Incorporating the cost parameter in the evaluation process is an important criterion for the acceptance of the SFRP sheet as an effective material for concrete enhancement. Thus, the cost effectiveness of the CFRP and the SFRP sheets are presented and compared.

The cost effectiveness parameter is defined through a strength efficiency scale, $S E_{f f}$, which is determined as the percentage increase in strength of the FRP confined concrete specimens, with respect to the unwrapped specimens, over the total cost involved with the construction and the FRP confinement of the concrete column as described in the following equation:

$$
S E_{f f}=\frac{\text { Percentage Increase in the Strength of FRP Confined Concrete Columns }}{\text { Total Cost of the FRP Confined Concrete Columns }}
$$

As the cost of the concrete, reinforcing steel, epoxy, and transportation are equivalent for all the columns, it is reasonable to ignore these costs for the calculation of the cost effectiveness parameter. Thus, the only varying cost parameters used in Equation (1) is the cost of the confining material and the labour costs.

Based on the 2011 market price (at the time this research was conducted), the cost of the SFRP and the CFRP sheets were $25 \$ / \mathrm{m}^{2}$ and $45 \$ / \mathrm{m}^{2}$, respectively [21]. Therefore, the cost of the SFRP sheet is $56 \%$ of the CFRP sheet cost. However, the labour costs involved for the SFRP wrapped concrete columns are higher than the CFRP wrapped concrete columns due to the time and effort required to handle and wrap the stiff SFRP sheets. According to the laboratory experience gained during the implementation of this project, it was noted that the time required to wrap a column with the SFRP sheet is approximately double the time required to wrap the column with the CFRP sheet. This was due to the facts that the SFRP sheet is not as flexible as the CFRP sheet and the requirement of using sonotubes around the wrapped stiff SFRP sheets will prevent it from opening and detaching from the concrete surface. Clamps were also used to tighten the sonotubes in order to ensure that the SFRP sheets are in complete contact with the circumferential concrete surface, such a requirement was not necessary when flexible CFRP sheets were wrapped around the concrete column. Thus, the labour cost 
for the SFRP wrapped concrete column is estimated to be twice the labour cost involved for CFRP wrapped concrete column.

In order to calculate the total cost of the FRP confined concrete column, an appropriate labour hourly rate has to be determined. According to a recent study performed by Abdelrahman and El-Hacha [27] on the cost effectiveness of the CFRP and the SFRP wrapped concrete columns, the labour cost has been normalized to yield a factor of 1 and 2 for the CFRP and the SFRP wrapped concrete columns, respectively. The normalized factors was based on the estimate that the labour cost of the concrete columns wrapped with SFRP sheets was twice that of the columns wrapped with the CFRP sheets. However, this technique provided a constant labour factor for the columns wrapped with the CFRP and SFRP sheets, regardless of the column size used and the number of layers confining the concrete columns. To overcome this issue, an appropriate labour hourly rate was determined in this study to account for the wrapping process of the FRP sheet, the size of the columns, and the number of FRP layers.

In 2011, the Government of Canada published the construction union wage rates for all construction professions across the various provinces in Canada [28]. A brief section of the data on the construction union wages rates can be found in Appendix A. In order to estimate a rate for the hourly labour wage, the average of all construction professions were calculated. According, the average labour cost was determined to be $\$ 33 / \mathrm{h}$. In the following sections, the cost effectiveness analysis accounted for the variation of the labour cost, which is depended on the FRP type, number of FRP layers, and the size of the concrete column.

\subsection{Cost Effectiveness of Large-Scale Columns}

The percentage increase in strength and the cost effectiveness parameters of the large-scale CFRP and SFRP wrapped concrete columns are presented in Figures 1 and 2, respectively. The analysis of the SFRP wrapped concrete columns indicated that the columns exposed to room temperature had higher cost effectiveness parameter, when compared to the columns subjected to environmental conditions. The columns NR-SFRP-RT, R-SFRP-RT, and R-SFRP-HV-RT had an increase in the cost effectiveness parameter by $51 \%, 21 \%$, and $11 \%$ over the conditioned columns NR-SFRP-EE, R-SFRP-EE, and R-SFRP-HV-EE, respectively. This is due to the fact that the conditioned SFRP wrapped concrete columns experienced fatigue due to the freeze-thaw cycling and developed residual stresses. These factors reduced the strength enhancement of the columns causing a reduction in the cost effectiveness parameter.

In order to determine the effect of strengthening the RC columns with two layers of SFRP sheets on the cost effectiveness parameter, the results were compared with the RC columns wrapped using one layer of the SFRP sheet. Strengthening the RC columns with two layers of the SFRP sheet having one sheet with the fibres in the longitudinal direction and one sheet with the fibres in the transverse direction (R-SFRP-HV-RT and R-SFRP-HV-EE) had an insignificant effect in terms of the strength enhancement (less than $15 \%$ difference), when compared to the RC columns wrapped with one layer of the SFRP sheet (R-SFRP-RT and R-SFRP-EE). This result is expected since the longitudinal layer of the SFRP sheet does not contribute to the axial stiffness of the columns and as a consequence, no significant strength gain is recognized due to the addition of this layer. However, the inclusion of an 
additional SFRP sheet has reduced the cost effectiveness parameter of the RC columns R-SFRP-HV-RT and R-SFRP-HV-EE strengthened with two layers of SFRP sheet by $40 \%$ and $33 \%$, when compared to the RC columns R-SFRP-RT and R-SFRP-EE wrapped with one layer of the SFRP sheet, respectively. Although the percentage increase in the strength of the columns wrapped with one layer and two layers of SFRP sheets were similar, strengthening the columns with an additional layer caused an increase in the total cost of the columns wrapped with two layers of SFRP sheets. The increased cost caused a reduction in the cost effectiveness parameter.

The effect of strengthening the RC column with SFRP sheet, after being exposed to severe environmental condition (R-SFRP-AEE), on the cost effectiveness parameter was determined by comparing the results with the RC columns wrapped with SFRP sheet before being environmentally exposed (R-SFRP-EE and R-SFRP-HV-EE). The column R-SFRP-AEE wrapped with one layer of the SFRP sheet after being subjected to environmental exposure had an enhanced cost effectiveness parameter by $77 \%$ and $163 \%$, over the columns R-SFRP-EE and R-SFRP-HV-EE, respectively, strengthened before being subjected to environmental conditions.

The analysis of the CFRP confined concrete columns summarized in Figure 2 provides a comparison between the CFRP wrapped non-reinforced concrete (NRC) columns and the reinforced concrete (RC) columns. The results indicate that the NRC columns wrapped with the CFRP sheets (NR-CFRP-RT and NR-CFRP-EE) had higher cost effectiveness parameters than the CFRP wrapped RC columns (R-CFRP-RT, R-CFRP-EE, R-CFRP-HV-RT, R-CFRP-HV-EE and R-CFRP-AEE). This is due to the fact that the increase in the confined concrete strength of the CFRP wrapped NRC columns was higher than the CFRP wrapped RC columns.

In order to determine the effect of environmental exposure on the CFRP wrapped concrete columns, a comparison between exposed and non-exposed columns was conducted. The CFRP wrapped RC columns subjected to room temperature (NR-CFRP-RT and R-CFRP-HV-RT) had higher cost effectiveness parameter than its corresponding columns exposed to environmental conditions (NR-CFRP-EE and R-CFRP-HV-EE). The RC columns NR-CFRP-RT and R-CFRP-HV-RT had higher cost effectiveness parameter by $34 \%$ and $82 \%$, respectively, when compared to the conditioned RC columns NR-CFRP-EE and R-CFRP-HV-EE. The results presented in Figure 2 also show a comparison between the cost effectiveness parameters of the RC columns wrapped with two layers of CFRP sheets and the RC columns wrapped with only one layer of the CFRP sheet. Strengthening the RC columns with two layers of CFRP sheets having one sheet with the fibres in the longitudinal direction and one sheet with the fibres in the transverse direction (R-CFRP-HV-EE) had a cost effectiveness parameter that is 7.5 times lower than the cost effectiveness parameter achieved by the RC columns wrapped with one layer of the CFRP sheet. It should be noted that the column R-CFRP-RT wrapped with one layer of SFRP sheet is an exception to the aforementioned discussion. It is strongly believed that accidental eccentricity applied during the experimental testing might have caused a slightly premature failure of the column.

The effect of wrapping the RC column with CFRP after being exposed to severe environmental conditions (R-CFRP-AEE) was investigated by comparing the results with the CFRP wrapped RC columns before being environmentally exposed (R-CFRP-EE and R-CFRP-HV-EE). The results show that column R-CFRP-AEE wrapped with one layer of CFRP sheet had a cost effectiveness parameter 
that is 1.6 and 12 times higher than the cost effectiveness parameters of columns R-CFRP-EE and R-CFRP-HV-EE, respectively.

The comparison between the cost effectiveness parameter of the columns wrapped with CFRP and SFRP is summarized in Figure 2. The cost effectiveness analysis clearly indicates that regardless of the internal reinforcement ratio, the type of environmental exposure, and the fibre orientation of the FRP sheet, the cost effectiveness of the columns strengthened with SFRP sheets is always superior to the columns strengthened with CFRP sheets. The reinforced and non-reinforced SFRP strengthened concrete columns experienced an enhancement in the cost effectiveness parameter that can reach up to 1.7 and 20 times higher than its corresponding reinforced and non-reinforced CFRP strengthened concrete columns, respectively.

Figure 1. Percentage increase in the strength of the SFRP and CFRP strengthened concrete columns.

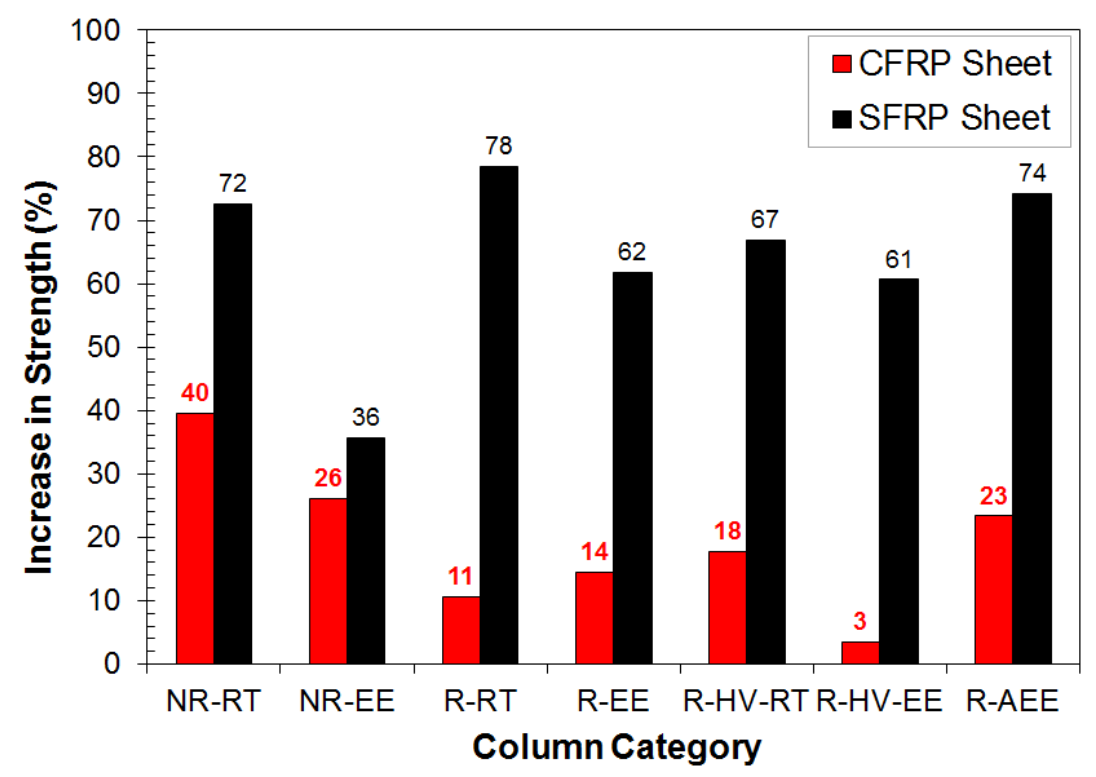

Figure 2. Cost effectiveness of the SFRP and CFRP strengthened concrete columns.

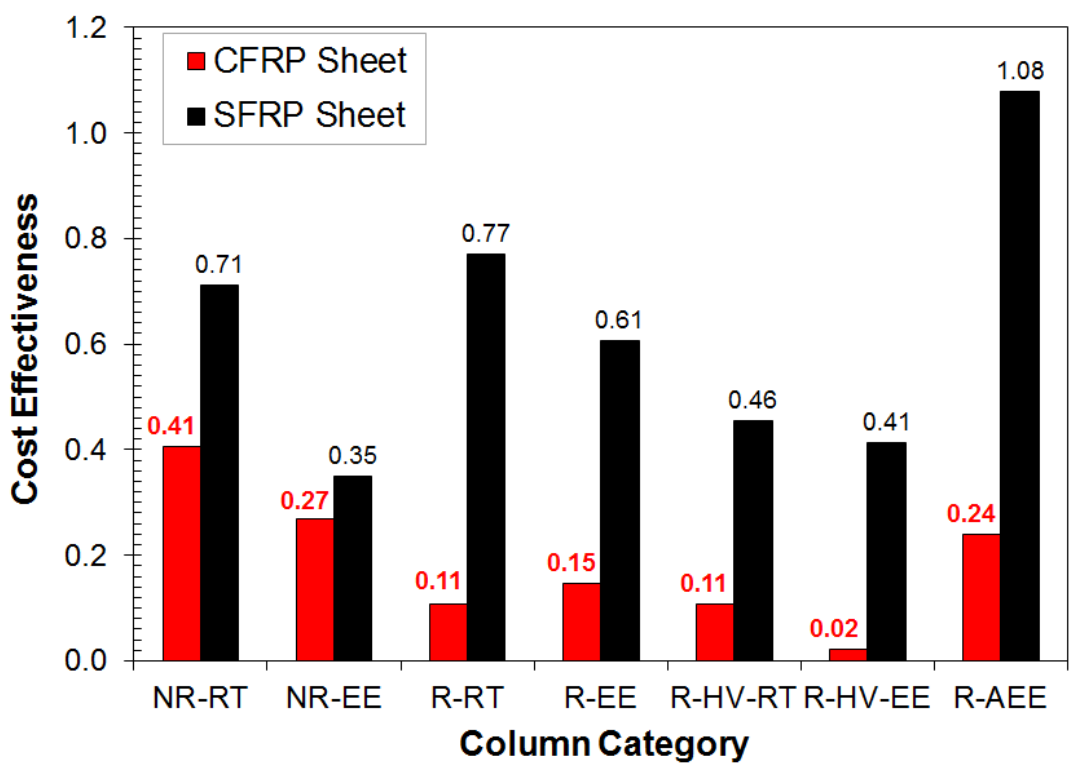




\subsection{Cost Effectiveness of Columns with Varying Aspect Ratio}

The analysis of the results for varying slenderness ratios of 2, 4, and 6 of RC columns wrapped with CFRP and SFRP sheets, in terms of the percentage increase in strength and the cost effectiveness parameter are summarized in Figures 3 and 4, respectively. In order to determine the effect of the slenderness ratio on the cost effectiveness parameter, a comparison of the results between the varying slenderness ratios of 2, 4, and 6 was conducted. A general trend of the data presented in Figure 4 can be recognized regarding the decrease in the cost effectiveness parameter as the slenderness ratio of the columns is increased. Based on the cost effectiveness analysis performed on the CFRP wrapped concrete columns, increasing the slenderness ratio from 2 to slenderness ratios of 4 and 6 caused a reduction in the cost effectiveness parameter by $42 \%$ and $48 \%$, respectively. The cost effectiveness analysis performed on the SFRP wrapped concrete columns with slenderness ratios of 4 and 6 experienced lower cost effectiveness parameter by $32 \%$ and $47 \%$, respectively, when compared to the SFRP wrapped concrete columns with a slenderness ratio of 2 . The main reason for the reduction in the cost effectiveness parameter is due to the lower strength enhancement and high costs involved with increasing the slenderness of the columns. Detailed discussion about the slenderness effects on the cost effectiveness parameter can be found in later sections of this paper.

In order to determine the efficiency of the FRP sheet in enhancing the cost effectiveness parameter, a comparison between the columns wrapped with CFRP and SFRP sheet with varying slenderness ratios was performed. The results presented in Figure 4 show that within the same group of the slenderness ratio, the columns wrapped with the SFRP sheets achieved higher cost effectiveness parameters than the columns wrapped with the CFRP sheets. The cost effectiveness parameter of the SFRP wrapped concrete columns with slenderness ratios of 2, 4, and 6 was higher by $348 \%, 321 \%$, and $226 \%$, respectively, over their corresponding columns wrapped with the CFRP sheets. Although the cost associated with wrapping the concrete columns with SFRP sheets is higher than the CFRP sheets, the strength enhancement of the SFRP wrapped concrete columns surpasses that of the CFRP wrapped concrete columns, resulting in higher cost effectiveness parameters.

Figure 3. Percentage increase in the strength of the aspect ratio columns wrapped with SFRP and CFRP sheets.

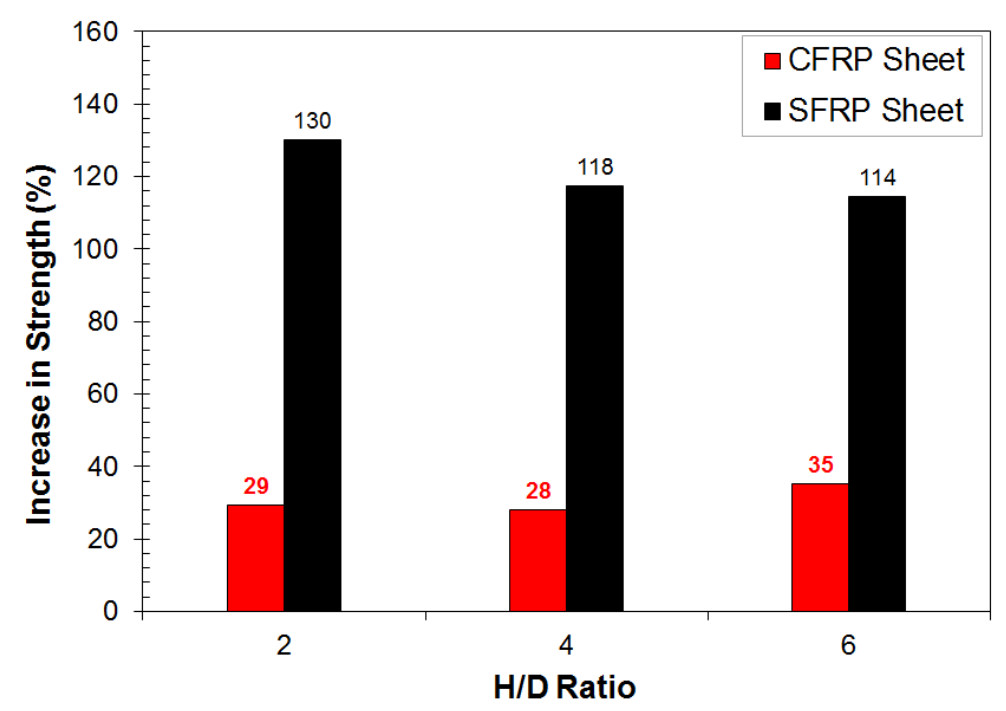


Figure 4. Cost effectiveness of the aspect ratio columns wrapped with SFRP and CFRP sheets.

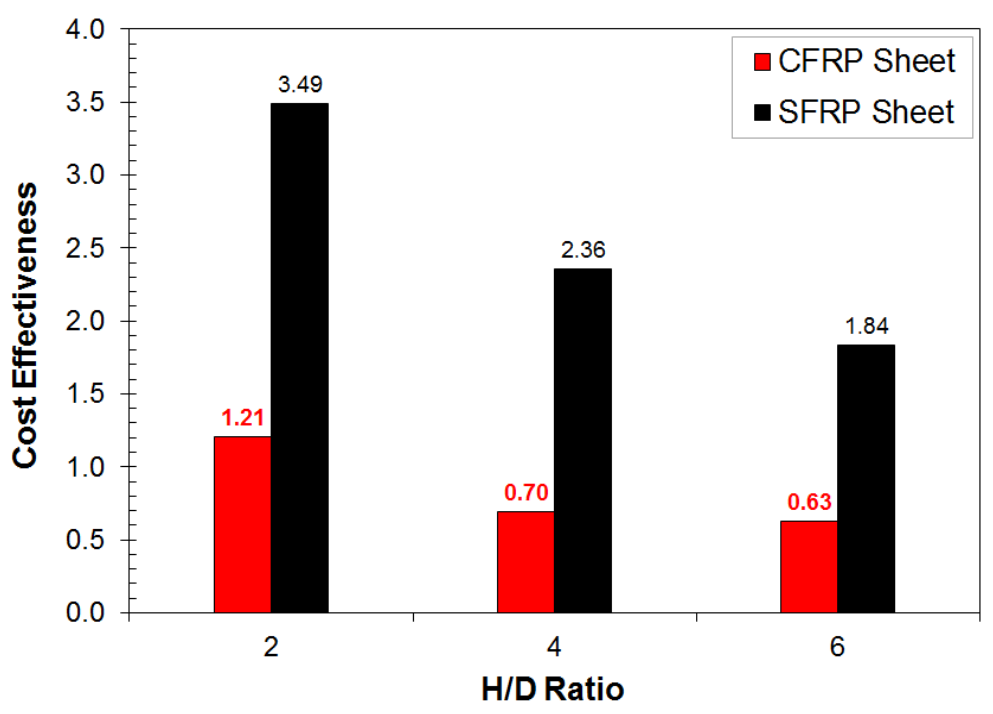

\section{Ductility Effectiveness}

Another method to evaluate the effectiveness of the various types of FRP sheets to confine RC columns is to consider the ductility effectiveness parameter. Similar to the cost effectiveness, the ductility effectiveness parameter is a function of the ductility gain relative to the total cost associated with the construction and the FRP confinement of the concrete column. The ductility of the columns was measured as the total area under the stress-strain curve up to the failure load of the experimentally tested SFRP or CFRP wrapped concrete columns. The failure load is defined as the load corresponding to the rupture of the confining FRP sheet. The ductility effectiveness parameter is very important when considering strengthening the columns subjected to seismic or eccentric loading. Thus, in this section, the ductility effectiveness of the columns confined with SFRP and CFRP sheets are evaluated and compared.

The ductility effectiveness is defined through a ductility efficiency scale, $D E_{f f}$, which is determined as the percentage increase in the ductility of the FRP wrapped columns, with respect to the unwrapped columns, over the total cost associated with the construction and the FRP confinement of the concrete column as described in the following equation:

$$
D E_{f f}=\frac{\text { Percentage Increase in the Ductility of FRP Confined Concrete Columns }}{\text { Total Cost of the FRP Confined Concrete Columns }}
$$

In the comparison of the ductility effectiveness parameter, only the labour cost and the cost of the CFRP/SFRP sheets are considered due to the reasons already mentioned above. It is important to note that in this section, only the ductility effectiveness parameter of the large-scale columns is presented. As previously mentioned, the data for the aspect ratio of the columns wrapped with CFRP sheets were tested by Bisby and Stratford [24]. There is not sufficient information presented in their paper to allow for the calculation of the ductility effectiveness parameter of the CFRP wrapped concrete columns with varying slenderness ratios. Thus, a comparison of the ductility effectiveness parameter to determine the efficiency of the FRP sheets is not applicable for the aspect ratio specimens. 
The results of the ductility effectiveness study, in terms of the percentage increase in the ductility and the ductility effectiveness parameter for the large-scale SFRP and CFRP wrapped RC columns are summarized in Figures 5 and 6, respectively. Unlike the cost effectiveness parameter, there is no general trend that can be recognized in the ductility effectiveness parameter within the groups of the CFRP and SFRP wrapped concrete columns. The reason can be related to the fact that the ductility effectiveness parameter depends on the area under the axial stress-axial strain curve. Several researchers [29-35] investigated the axial strain through a photographic method known as the digital image correlation technique. This technique functions by capturing various images at selected time intervals during the experimental testing. The axial strains are then measured by tracking pre-determined points along subsequent images using a MATLAB module (Mathworks Inc., Natick, MA, USA). The results from these investigations showed that the axial strain of the concrete columns is a highly varying parameter and its measurement significantly depends on the mounted location of the strain gauge on the column. This theory justifies that the irregular results of the ductility effectiveness parameter is due to the highly variable nature of the concrete.

The efficiency of the FRP sheets in enhancing the ductility effectiveness of the concrete columns is determined by comparing the ductility effectiveness parameter between the concrete columns wrapped with CFRP and SFRP sheets. It is important to mention that during the experimental testing, it was noted that the SFRP wrapped non-reinforced concrete column subjected to environmental exposure (NR-SFRP-EE) experienced premature failure as an accidental eccentricity was applied from the loading plates of the testing machine. Thus, if this column was to be ignored, the results from Figure 6 clearly show that regardless of the internal longitudinal reinforcement ratio, the type of environmental exposure, and the fibre orientation of the FRP sheet, the ductility effectiveness of the columns wrapped with the SFRP sheets is always superior to the columns wrapped with the CFRP sheets. The reinforced and non-reinforced SFRP wrapped concrete columns experience an enhancement in the ductility effectiveness parameter that can reach up to 3 and 16 times higher than its corresponding CFRP wrapped concrete columns, respectively.

Figure 5. Percentage increase in the ductility of the SFRP and CFRP wrapped concrete columns.

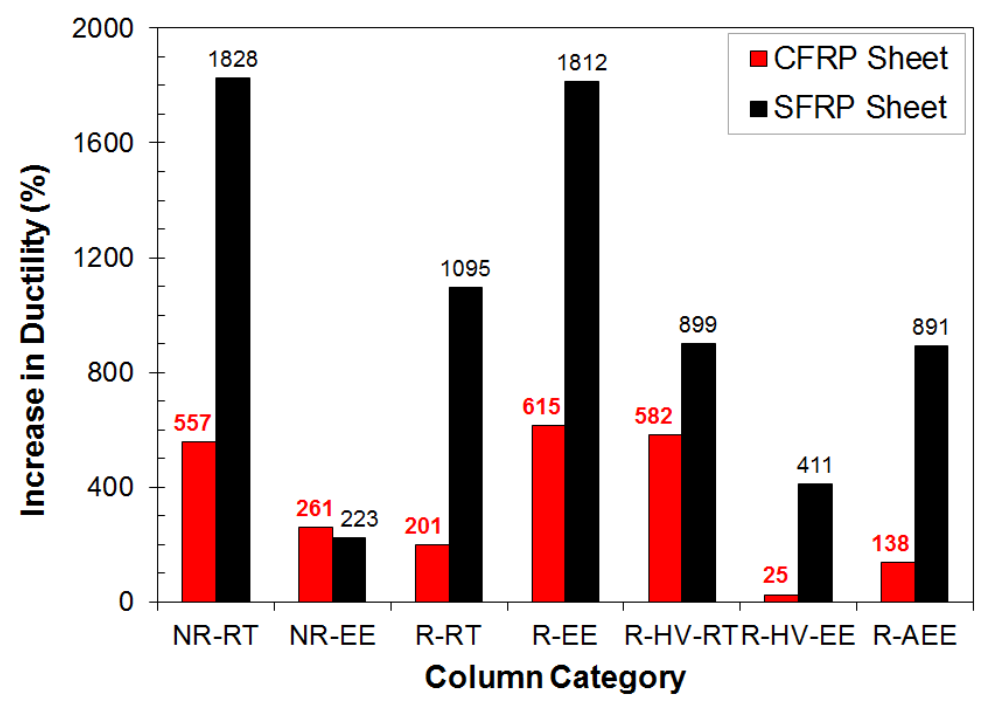


Figure 6. Ductility effectiveness of the SFRP and CFRP wrapped concrete columns.

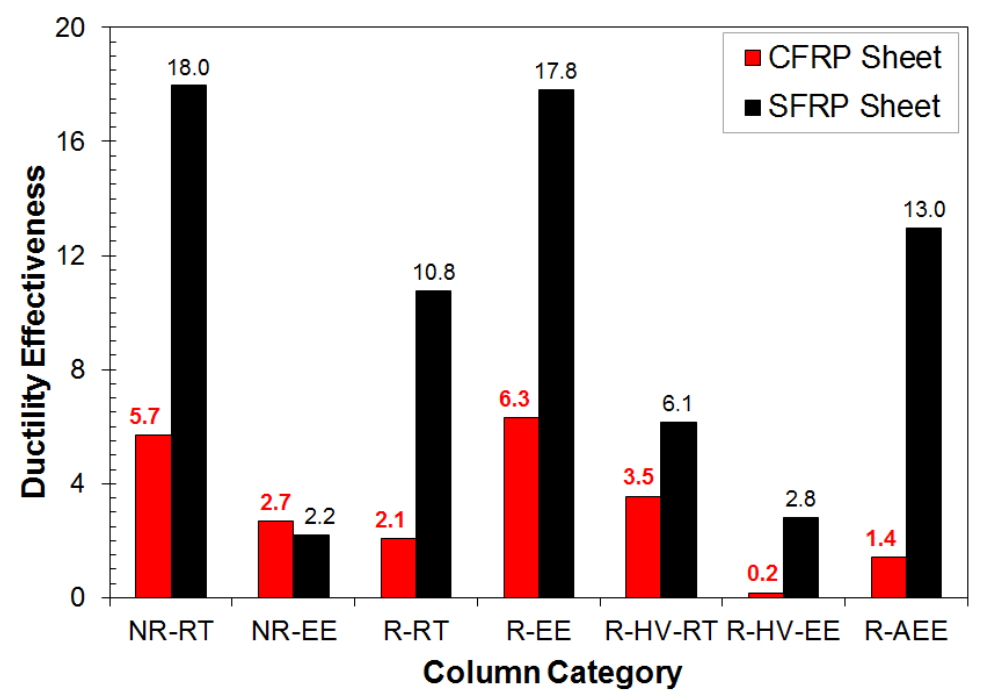

\section{Analytical Prediction of Cost Effectiveness Parameter}

One of the most critical components in the design process is to determine the cost effectiveness parameter. The cost effectiveness parameter provides information to the designer regarding the effectiveness of the confinement material, relative to its strength and the total cost involved. However, there is no information available to the designer in the literature or in the current design codes/guidelines to predict the cost effectiveness parameter. Thus, one of the objectives of this investigation presented in this section is to develop a procedure to analytically predict the cost effectiveness of concrete columns wrapped with SFRP sheets.

In order to predict the cost effectiveness parameter, the initial step is to predict the ultimate confined concrete strength of columns wrapped with SFRP sheets. Recently, Abdelrahman and El-Hacha [23] developed an analytical model to predict the confined concrete strength of columns wrapped with SFRP sheets. The equation incorporates the unconfined concrete strength, a reduction factor and the confinement pressure. The results presented in their study showed that the analytical model was able to predict the ultimate confined concrete strength of SFRP wrapped columns with high accuracy, when compared with the experimental data. It is worth mentioning that an analytical prediction of the ductility effectiveness is not presented in this paper due to the lack of a reliable and accurate model available in the literature to predict the axial strain of concrete columns wrapped with SFRP sheets. Once the SFRP confined concrete strength is determined, the percentage increase in the strength, with respect to the unconfined concrete column can be calculated. The next step is to determine the total cost involved with the construction and the FRP confinement of the concrete column. Then, Equation (1) is used to determine the cost effectiveness parameter of the SFRP confined concrete column. A detailed procedure to estimate the cost effectiveness parameter of concrete columns confined with SFRP sheets can be found in Appendix B. It is important to recognize that the unit weight of the SFRP sheets is heavier than that of the CFRP sheets. Based on the designer's selection of the transportation mode, it is recommended to incorporate this data into the total cost of the FRP sheet for a higher accuracy of the generated results. 
The accuracy of the proposed procedure to analytically predict the cost effectiveness of the SFRP sheet can be validated by comparing the analytical results with the experimental data. Figure 7 shows the cost effectiveness comparison between the analytical results and the experimental data for columns wrapped by one layer of SFRP sheets with aspect ratios of 2, 4 and 6. Accordingly, the percentage error between the experimental data and the analytical results for the SFRP wrapped concrete columns with aspect ratios of 2,4 and 6 were $7 \%, 1 \%$ and $2 \%$, respectively. The compared results clearly indicate a good agreement between the cost effectiveness from the experimental data with the analytically predicted data. Therefore, a parametric study was conducted to determine the variation of the concrete strength, number of SFRP layers, and the size and slenderness effects on the cost effectiveness of the concrete columns wrapped with the SFRP sheets.

Figure 7. Cost effectiveness parameter from the analytical and experimental data.

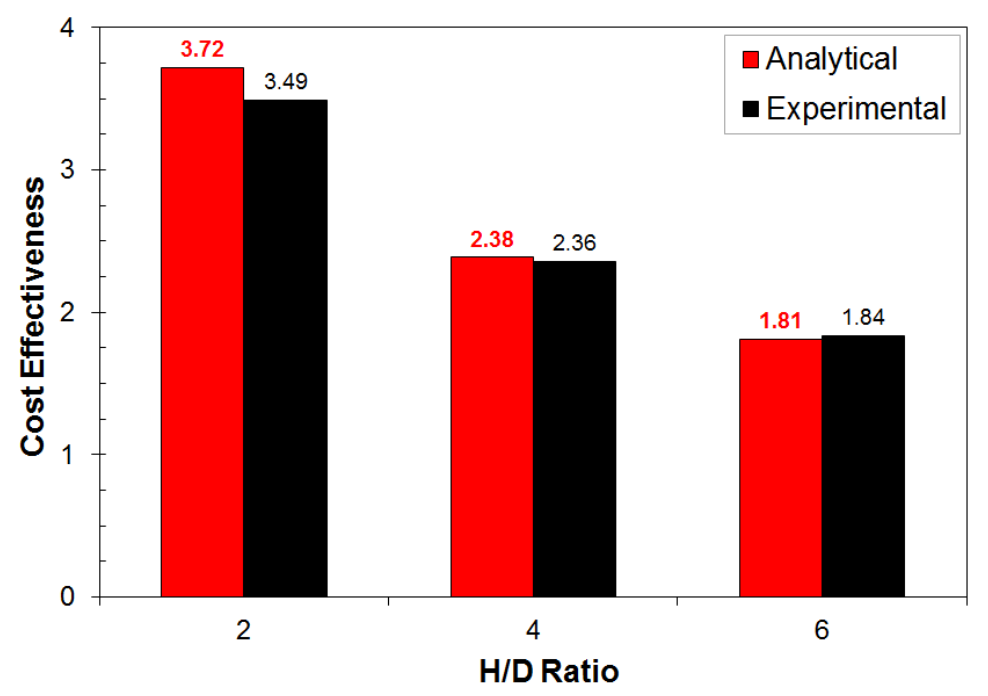

\subsection{Parametric Study of the Cost Effectiveness}

The parametric study included in this section involves investigating several factors that affect the cost effectiveness of the SFRP confined concrete columns. The parameters investigated were the concrete strength, number of SFRP layers, size and slenderness effects. In order to determine the cost effectiveness of the SFRP confined concrete columns, Equation (1) was used. The numerator of this equation can be determined experimentally or through analytical equations. The denominator of Equation (1) is based on estimating the total cost involved with the construction and the confinement of SFRP concrete columns. As mentioned previously, the only varying parameters associated with the total costs are the material cost of the SFRP and the labour cost. These costs are dependent on the size of the column and the number of SFRP layers. Table 4 shows the various column sizes and number of SFRP layers included in the parametric study, along with their respective material costs, labour costs, and the total costs. 
Table 4. Summary of the material, labour and the total cost of the SFRP confined concrete columns.

\begin{tabular}{|c|c|c|c|c|c|c|c|}
\hline $\begin{array}{c}\text { Diameter, } \\
D(\mathbf{m m})\end{array}$ & $\begin{array}{l}\text { Height, } \\
H(\mathrm{~mm})\end{array}$ & $\begin{array}{l}\text { No. of SFRP } \\
\text { layer(s) }\end{array}$ & $\begin{array}{c}\text { Labour } \\
\text { Hours }\end{array}$ & $\begin{array}{c}\text { Total } \\
\text { Area }\left(\mathbf{m}^{2}\right)\end{array}$ & $\begin{array}{c}\text { Material } \\
\text { Cost (\$) }\end{array}$ & $\begin{array}{l}\text { Labour } \\
\text { Cost (\$) }\end{array}$ & $\begin{array}{c}\text { Total } \\
\text { Cost }(\$)\end{array}$ \\
\hline \multirow{3}{*}{150} & \multirow{3}{*}{300} & 1 & 1.00 & 0.17 & 4.28 & 33.00 & 6.78 \\
\hline & & 2 & 1.50 & 0.31 & 7.82 & 57.32 & 8.21 \\
\hline & & 3 & 2.00 & 0.45 & 11.35 & 77.35 & 8.90 \\
\hline \multirow{3}{*}{150} & \multirow{3}{*}{600} & 1 & 1.25 & 0.34 & 8.57 & 41.25 & 49.82 \\
\hline & & 2 & 1.75 & 0.63 & 15.64 & 57.75 & 73.39 \\
\hline & & 3 & 2.25 & 0.91 & 74.25 & 74.25 & 96.96 \\
\hline \multirow{3}{*}{150} & \multirow{3}{*}{900} & 1 & 1.50 & 0.51 & 12.85 & 49.50 & 62.35 \\
\hline & & 2 & 2.00 & 0.94 & 23.46 & 66.00 & 89.46 \\
\hline & & 3 & 2.50 & 1.36 & 34.06 & 82.50 & 116.56 \\
\hline 150 & 600 & 1 & 1.25 & 0.34 & 8.57 & 41.25 & 49.82 \\
\hline 200 & 800 & 1 & 1.75 & 0.58 & 14.57 & 57.75 & 72.32 \\
\hline 300 & 1200 & 1 & 2.00 & 1.25 & 31.27 & 66.00 & 97.27 \\
\hline
\end{tabular}

\subsection{Effect of Varying Slenderness Ratio and Concrete Strength}

In order to understand the slenderness effects on the cost effectiveness parameter of the SFRP confined concrete columns, the slenderness ratio was varied between 2,4 , and 6 . In addition, for each slenderness ratio, the concrete strength was varied between 20,30, and $40 \mathrm{MPa}$. According to Figure 8, the effect of the concrete strength on the cost effectiveness parameters shows that the lowest concrete strength $(20 \mathrm{MPa})$ had the highest cost effectiveness parameter. The columns with a $20 \mathrm{MPa}$ concrete strength can achieve a percentage increase in the cost effectiveness parameter by up to $29 \%$ and $43 \%$, when compared to columns with a concrete strength of $30 \mathrm{MPa}$ and $40 \mathrm{MPa}$, respectively. This is due to the fact that the lower strength concrete allows for higher strength enhancement. As the concrete strength increases, the percentage increase in the strength decreases, which results in a lower cost effectiveness parameter.

The effect of the slenderness ratio on the cost effectiveness parameter from Figure 8 shows that regardless of the variation in the concrete strength, an increase in the slenderness ratio from 2 to 4 caused a reduction in the cost effectiveness parameter by $40 \%$, whereas increasing the slenderness ratio from 4 to 6 caused a further decrease in the cost effectiveness parameter by $32 \%$. The main reason behind the reduction in the cost effectiveness parameter can be explained through buckling instability that occurs as the specimen height increases and becomes more slender. Buckling instability reduces the strength of the concrete and also causes non-uniform confinement pressure. As a result, the percentage increase associated with increasing the slenderness ratio of the column decreases, adversely affecting the cost effectiveness parameter. In addition, the lower cost effectiveness parameter is attributed to the lower strength and higher costs involved with increasing the slenderness ratio of the column. 
Figure 8. Cost effectiveness of the SFRP confined concrete columns with varying slenderness ratios and concrete strengths.

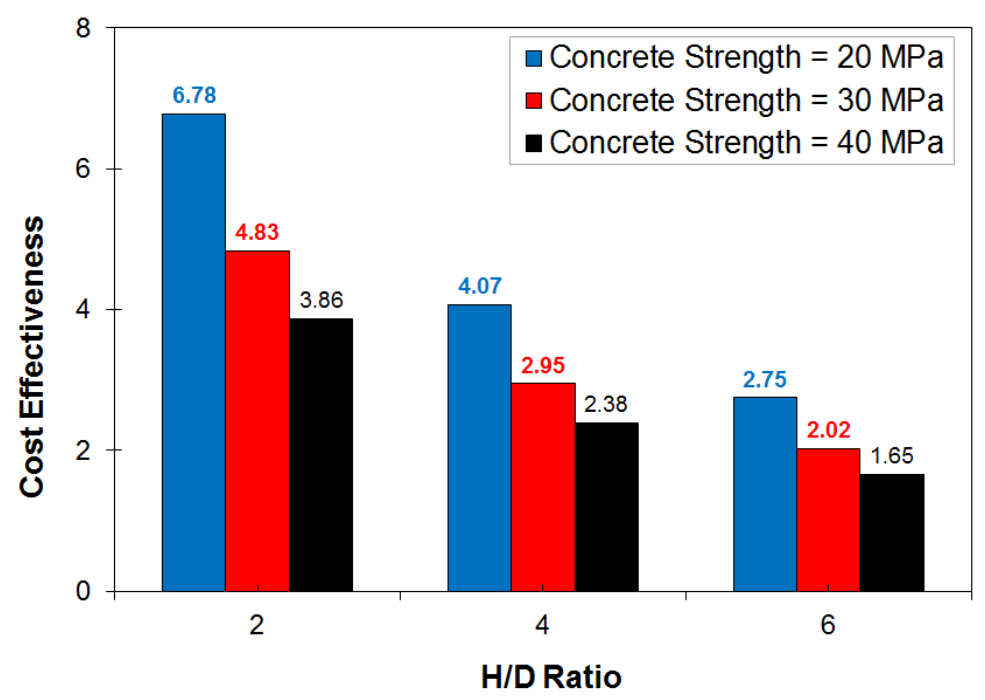

\subsection{Effect of Varying the Number of SFRP Layers}

Experimental research [16,20] has proven that increasing the number of FRP layers enhances the concrete strength of the wrapped column. Yet, an overall analysis that includes cost considerations is essential to determine the effectiveness of increasing the number of SFRP layers to enhance the strength, relative to the total cost involved. Thus, a parametric study was conducted that included varying the number of SFRP layers, the concrete strength, and the slenderness ratio of the columns. The number of SFRP sheets used to confine the concrete columns that were considered in this analysis was 1 layer, 2 layers, and 3 layers. The concrete strength varied between 20, 30 and $40 \mathrm{MPa}$. The ratios of the column slenderness adopted for this study were 2,4 , and 6.

The analysis obtained from increasing the number of SFRP layers and the slenderness ratio, along with varying concrete strengths is presented in Figures 9-11. As mentioned earlier, the highest cost effectiveness parameter is achieved by the use of concrete columns with the lowest strength, as demonstrated through the comparison of the cost effectiveness parameter results for the SFRP wrapped concrete columns with aspect ratio of 4 with varying number of SFRP layers and concrete strengths. These results indicate that columns with $20 \mathrm{MPa}$ concrete strengths, wrapped with one layer of SFRP sheet can achieve up to $28 \%$ and $42 \%$ greater cost effectiveness over columns with concrete strength of 30 and $40 \mathrm{MPa}$, respectively. The columns wrapped by two layers of SFRP sheets with a $20 \mathrm{MPa}$ concrete strength have higher cost effectiveness over the 30 and $40 \mathrm{MPa}$ concrete columns by $30 \%$ and $46 \%$, respectively. The cost effectiveness of the $20 \mathrm{MPa}$ concrete strength columns wrapped by three layers of SFRP sheets was higher by $31 \%$ and $47 \%$, when compared to columns with 30 and $40 \mathrm{MPa}$ concrete strength, respectively. Similar percentage increases were also achieved for the SFRP confined concrete columns with aspect ratios of 2 and 6.

A general trend can be observed from Figures 9-11, indicating that within the same concrete group, the percentage increase in the cost effectiveness parameter gained by increasing the number of SFRP layers are similar, regardless the variation in the slenderness ratio of the column. The results also show that a higher cost effectiveness parameter is achieved by increasing the number of SFRP layers. The 
columns with $20 \mathrm{MPa}$ concrete strength experienced up to $25 \%$ and $10 \%$ increases in the cost effectiveness parameter as a result of increasing the number of SFRP layers from one layer to two layers and three layers, respectively (Figure 9). The cost effectiveness parameter was enhanced by up to $20 \%$ and $9 \%$ for the $30 \mathrm{MPa}$ concrete columns wrapped with two layers and three layers of the SFRP sheets, respectively, when compared to the columns wrapped with one layer of SFRP sheets (Figure 10). The columns with $40 \mathrm{MPa}$ concrete strength wrapped with two layers and three layers of the SFRP sheets had higher cost effectiveness parameters by up to $16 \%$ and $7 \%$, respectively, over the concrete columns wrapped with one layer of the SFRP sheet (Figure 11).

Figure 9. Cost effectiveness of SFRP confined concrete columns with $20 \mathrm{MPa}$ concrete strengths and varying numbers of SFRP layers and slenderness ratios.

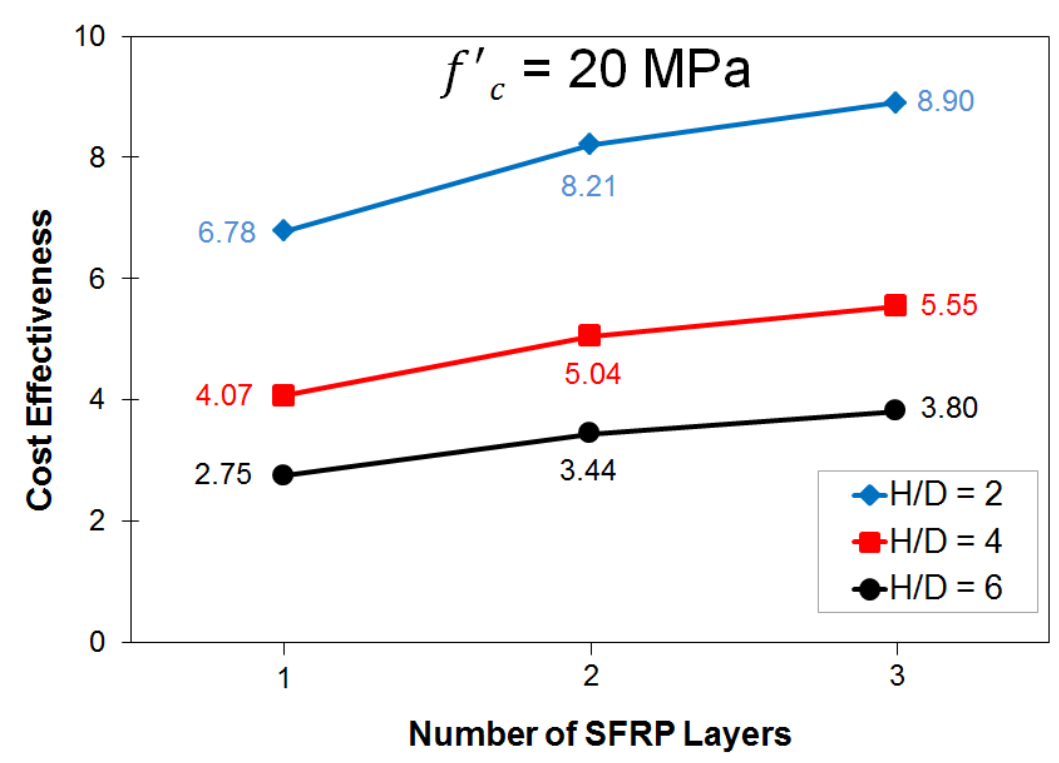

Figure 10. Cost effectiveness of SFRP confined concrete columns with $30 \mathrm{MPa}$ concrete strength and varying numbers of SFRP layers and slenderness ratios.

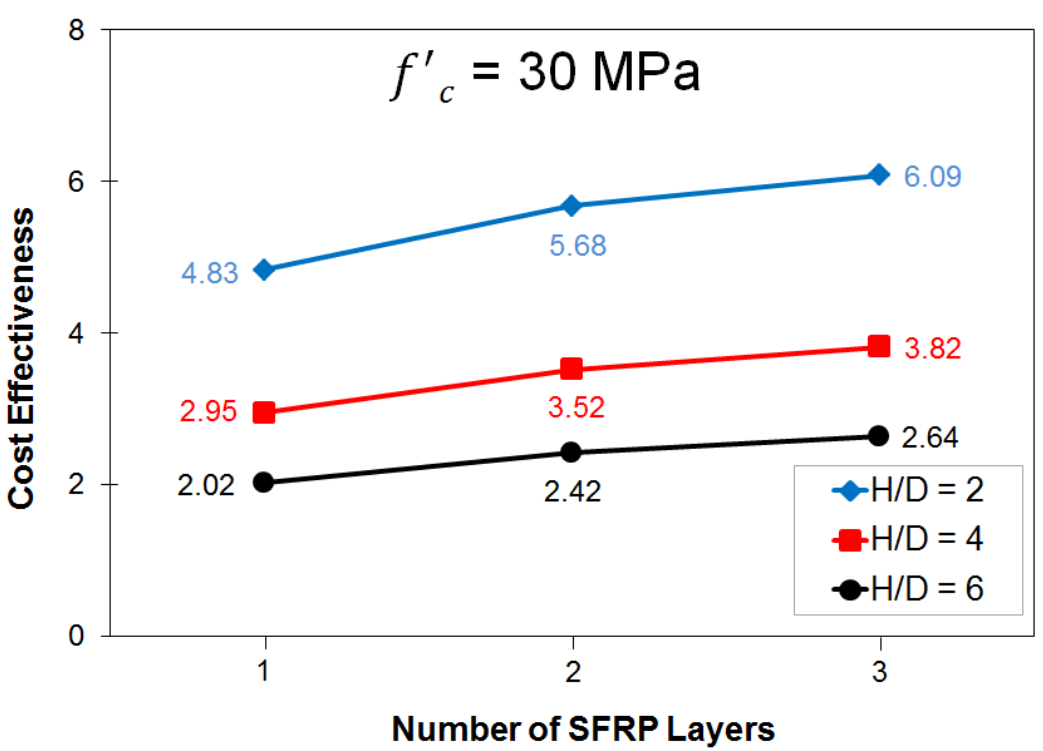


Figure 11. Cost effectiveness of SFRP confined concrete columns with $40 \mathrm{MPa}$ concrete strengths and varying numbers of SFRP layers and slenderness ratios.

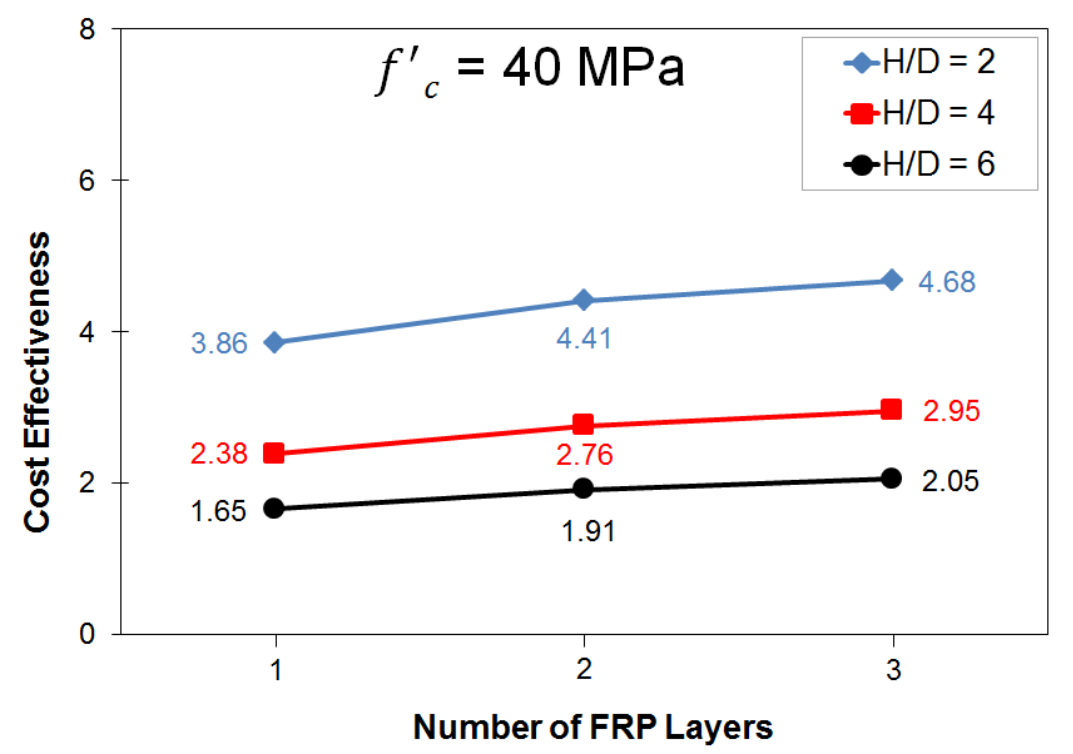

The increase in the number of SFRP layers directly enhances the confinement pressure. The enhanced confinement pressure leads to higher strength, thus increasing the cost effectiveness parameter of the SFRP confined concrete column. It should also be noted that the percentage increase in the cost effectiveness parameter decreases with the increase in the number of SFRP layers. Despite the fact that the concrete strength is increased as the number of SFRP layers increases, the lower percentage increase in the cost effectiveness parameter is achieved because the total cost involved in the construction of the SFRP confined concrete column also increases.

\subsection{Effect of the Column Size}

One of the major factors that affect the cost effectiveness parameter is the size effects of the SFRP wrapped concrete columns. The column sizes included in this study were $150 \mathrm{~mm} \times 500 \mathrm{~mm}$, $200 \mathrm{~mm} \times 800 \mathrm{~mm}$, and $300 \mathrm{~mm} \times 1200 \mathrm{~mm}$. The column sizes were selected to maintain a constant aspect ratio of 4 for comparison purposes. The main purpose of this investigation was to determine the size effects along with varying concrete strength of 20,30 , and $40 \mathrm{MPa}$, on the cost effectiveness parameter of concrete columns wrapped with SFRP sheets. The results of the size effect study are summarized in Figure 12.

The results clearly indicate that within the same size group, columns with lower concrete strengths achieved higher cost effectiveness parameter due to aforementioned reasons. The columns with $20 \mathrm{MPa}$ concrete strengths can achieve higher cost effectiveness parameters by up to $28 \%$ and $42 \%$ over the columns with 30 and $40 \mathrm{MPa}$ concrete strengths, respectively. A general trend can be observed regarding the fact that while maintaining a constant concrete strength, an increase in the size of the columns significantly reduces the cost effectiveness parameter of the SFRP wrapped concrete columns. The results in Figure 12 show that increasing the size of the column from $150 \mathrm{~mm} \times 500 \mathrm{~mm}$ to $200 \mathrm{~mm} \times 800 \mathrm{~mm}$ and $300 \mathrm{~mm} \times 1200 \mathrm{~mm}$ can reduce the cost effectiveness parameter by up to $45 \%$ and $70 \%$, respectively. 
The small scale-specimens are mainly affected by the restraining influence of the end bearing plates, which leads to non-homogeneities and produces results that are not representative of the large-scale columns. Thus, the size effect is an important parameter to be investigated in relation to the cost effectiveness parameter. The size of the specimen significantly affects the confinement pressure applied to the concrete. As the size of the specimen increases, the confinement pressure decreases resulting in lower strength enhancement. In addition, increasing the size of the specimens involve higher costs. The combined factors of lower strength enhancement with higher total costs leads to lower cost effectiveness as the size of the column increases.

Figure 12. Cost effectiveness of SFRP confined concrete columns with varying column sizes and concrete strengths.

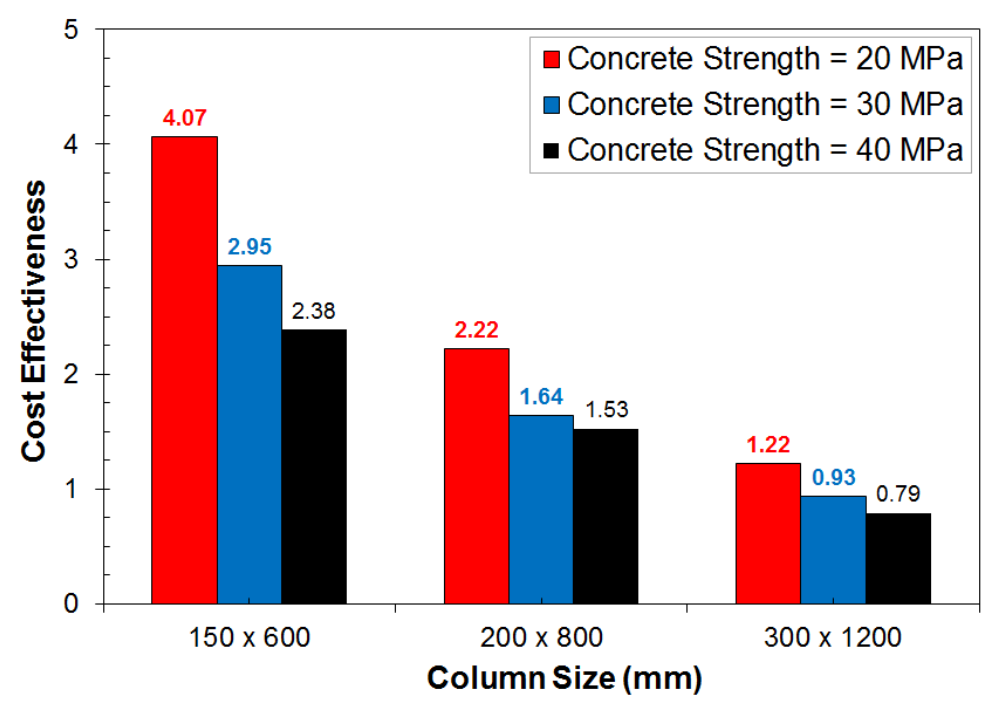

\section{Conclusions}

A cost and ductility effectiveness study was conducted on concrete columns wrapped with CFRP and SFRP sheets experimentally tested under uniaxial compression loading. An analytical procedure was also proposed to predict the cost effectiveness parameter of concrete columns wrapped with the SFRP sheets. The effect of several parameters such as the concrete strength, the number of SFRP layers, and the size and the slenderness of the SFRP wrapped concrete columns were analytically investigated.

Based on the current study, the cost and ductility effectiveness investigation showed that the SFRP wrapped columns were always superior to the columns wrapped with CFRP sheets. The results presented in this paper highlight the importance of cost considerations, while determining the overall efficiency of the FRP sheet for confining the concrete column. The strength and ductility enhancement of various fibre orientation of the FRP sheet $\left(0^{\circ}\right.$ for the circumferential direction and $90^{\circ}$ for the longitudinal direction) can be tremendous. However, when the cost criteria are considered, the overall beneficial value of the strengthening system can be negligible. Thus, an optimum design for certain FRP strengthening configurations can be attained using cost and ductility effectiveness analysis.

Comparison between the cost effectiveness parameters determined experimentally with those analytically predicted showed good agreement. The proposed method provides a new tool for designers to investigate the cost effectiveness parameter of SFRP wrapped concrete columns, allowing 
for optimum and efficient strengthening designs. However, further investigation is required to develop an analytical procedure to predict the ductility effectiveness of the SFRP wrapped concrete columns. Despite the wide database regarding FRP wrapped concrete columns; there is a lack of a reliable and accurate models to predict the axial strain of SFRP confined concrete columns. The proposal of a critically needed model is an initial step towards understanding the ductility effectiveness behaviour of SFRP wrapped concrete columns.

\section{Acknowledgments}

The authors would like to express their gratitude to Hardwire for providing the SFRP sheets, Sika Canada for providing the CFRP sheets and the epoxy adhesive, and Lafarge Canada for providing the ready-mix concrete. The authors are also grateful to the University of Calgary for the financial support to this research project.

\section{Author Contributions}

The authors contributed equally to this work. The authors designed the experimental program, analyzed the data, developed the analytical model, and wrote the manuscript.

\section{Conflicts of Interest}

The authors declare no conflict of interest.

\section{Appendix A}

Figure A1. A brief section of the data on the construction union wages rates [28].

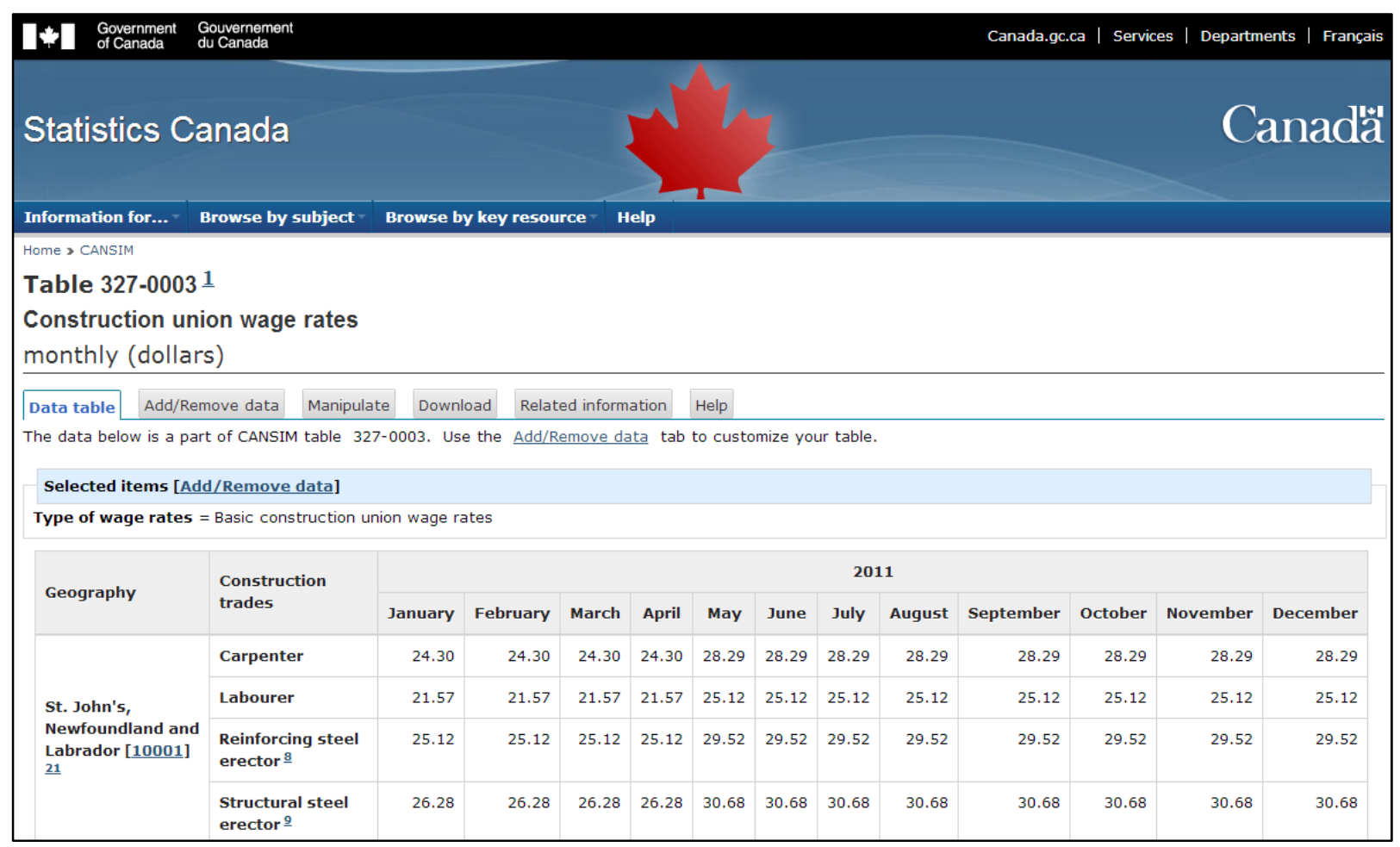




\section{Appendix B}

The procedure proposed to analytically predict the cost effectiveness of the SFRP sheet is as follows:

1. Determine the mechanical properties of the concrete and the SFRP sheets to be used in the design.

2. Determine the confinement pressure $\left(f_{l}\right)$, which is function of the number of FRP layers $(n)$, the thickness of the FRP sheet $\left(t_{f}\right)$, the SFRP ultimate tensile strain $\left(\varepsilon_{\text {SFRP }}\right)$, the modulus of elasticity of the FRP sheet $\left(E_{f}\right)$, and the diameter of the column $\left(D_{g}\right)$, using the following equation:

$$
f_{l}=\frac{2 n t_{f} \varepsilon_{\mathrm{SFRP}} E_{f}}{D_{g}}
$$

3. Calculate the reduction factor $(\kappa)$, which is a function of the aspect ratio of the column $(H / D$, where $H$ and $D$ refer to the height and the diameter of the column, respectively), using the following equation:

$$
\kappa=\frac{1}{0.7+0.15\left(\frac{H}{D}\right)}
$$

4. Determine the ultimate confined concrete strength of the SFRP wrapped column $\left(f_{c u}^{\prime}\right)$, which is a function of the unconfined concrete strength $\left(f_{c o}^{\prime}\right)$, the reduction factor $(\kappa)$ and the confinement pressure $\left(f_{l}\right)$, using the following equation:

$$
f_{c u}^{\prime}=1.35 f_{c o}^{\prime}+2.7 \kappa f_{l}
$$

5. Determine the percentage strength increase of the SFRP wrapped concrete column, with respect to the unwrapped concrete column.

6. Determine the total cost involved with the construction and the FRP confinement of the concrete column.

7. Calculate the cost effectiveness parameter $\left(S E_{f f}\right)$, using the following equation:

$$
S E_{f f}=\frac{\text { Percentage Increase in the Strength of FRP Confined Concrete Columns }}{\text { Total Cost of the FRP Confined Concrete Columns }}
$$

\section{References}

1. Karbhari, V.; Eckel, D. Effect of cold regions climate on composited jacketed-concrete columns. J. Cold Reg. Eng. 1994, 8, 73-86.

2. Nanni, A.; Bradford, N.M. FRP jacketed concrete under uniaxial compression. Constr. Build. Mater. 1995, 9, 115-124.

3. Karbhari, V.; Gao, Y. Composited jacketed concrete under uniaxial compression-Verification of simple design equations. J. Mater. Civ. Eng. ASCE 1997, 9, 185-193.

4. Mirmiran, A.; Shahawy, M. Behavior of concrete columns confined by fiber composites. J. Struct. Eng. ASCE 1997, 123, 583-590. 
5. Toutanji, H. Stress-strain characteristics of concrete columns externally confined with advanced fiber composite sheets. ACI Mater. J. 1999, 96, 397-404.

6. Toutangi, H.; Deng, Y. Strength and ductility performance of concrete axially loaded members confined with AFRP composite sheets. Compos. Part B Eng. 1999, 33, 255-261.

7. Karbhari, V.; Rivera, J.; Dutta, P. Effect of short-term freeze-thaw cycling on composite confined concrete. J. Compos. Constr. ASCE 2000, 6, 35-40.

8. Karbhari, V. Response of fiber reinforced polymer confined concrete exposed to freeze and freeze-thaw regimes. J. Compos. Constr. ASCE 2000, 6, 35-40.

9. Pessiki, S.; Harries, K.; Kestner, J.; Sause, R.; Ricles, J. Axial behavior of reinforced concrete columns confined with FRP jackets. J. Compos. Constr. ASCE 2001, 5, 237-245.

10. Lam, L.; Teng, J.G. Ultimate condition of fiber reinforced polymer-confined concrete. J. Compos. Constr. ASCE 2004, 8, 539-548.

11. Masia, M.J.; Gale, T.N.; Shrive, N.G. Size effects in axially loaded square section concrete prisms strengthened using carbon fiber reinforced polymer wrapping. Can. J. Civ. Eng. 2004, 13, 1-13.

12. Thériault, M.; Neale, K.W.; Claude, S. Fiber-reinforced polymers-confined circular concrete columns: Investigation of size and slenderness effects. J. Compos. Constr. ASCE 2004, 8, 323-331.

13. Matthys, S.; Toutanji, H.; Taerwe, L. Stress-strain behavior of large-scale circular columns confined with FRP composites. J. Struct. Eng. ASCE 2006, 132, 123-133.

14. El-Hacha, R.; Green, M.; Wight, G. Effect of severe environmental exposures on CFRP wrapped concrete columns. J. Compos. Constr. ASCE 2010, 14, 83-93.

15. Thermou, G.E.; Pantazopoulou, S.J. Metallic fabric jackets: An innovative method for seismic retrofitting of substandard RC prismatic members. Struct. Concr. 2007, 8, 35-46.

16. El-Hacha, R.; Mashrik, M.A. Effect of SFRP confinement on circular and square columns. Eng. Struct. 2012, 36, 379-393.

17. El-Hacha, R.; Abdelrahman, K. Slenderness effects of circular concrete specimens confined with SFRP sheets. Compos. Part B Eng. 2013, 44, 152-166.

18. Menna, C.; Asprone, D.; Ferone, C.; Colangelo, F.; Balsamo, A.; Prota, A.; Cioffi, R.; Manfredi, G. Use of geopolmers for composite external reinforced of RC members. Compos. Part B 2013, 45, $1667-1676$.

19. Thermou, G.; Katakalos, K.; Mano, G. Concrete confinement with steel-reinforced grout jackets. Mater. Struct. 2014, 2014, doi:10.1617/s11527-013-0239-6.

20. Mashrik, M.A. Performance Evaluation of Circular and Square Columns Wrapped with CFRP and SFRP Sheets. Master's Thesis, Department of Civil Engineering, University of Calgary, Calgary, AB, Canada, 2011.

21. Abdelrahman, K. Effectiveness of Steel-fibre Reinforced Polymer for Confining Circular Concrete Coldumns. Master's Thesis, Department of Civil Engineering, University of Calgary, Calgary, AB, Canada, 2011.

22. Abdelrahman, K.; El-Hacha, R. Behaviour of large scale columns wrapped with CFRP and SFRP sheet. J. Compos. Constr. ASCE 2012, 16, 430-439.

23. Abdelrahman, K.; El-Hacha, R. Strength Prediction of SFRP Confined Concrete Columns. In Proceedings of the 11th International Symposium on Fiber Reinforced Polymers for Reinforced Concrete Structures (FRPRCS-11) Conference, Guimaraes, Portugal, 26-28 June 2013; p. 9. 
24. Bisby, L.; Stratford, T. The ultimate condition of FRP confined concrete columns: New experimental observations \& insight. In Proceedings of the 5th International Conference on FRP Composites in Civil Engineering (CICE 2010) Conference, Beijing, China, 27-29 September 2010; pp. 599-602.

25. Sikawrap ${ }^{\circledR}$ Hex 230C. Product Data Sheet: Carbon Fibre Fabric for Structural Strengthening System, Edition 06.2010/v1. Available online: http://ca01.webdms.sika.com/fileshowdo?documentID=582 (accessed on 21 February 2011).

26. Hardwire. Hardwire Composite Armor System. Available online: http://www.hardwirellc.com (accessed on 5 January 2011).

27. Abdelrahman, K.; El-Hacha, R. Cost and ductility effectiveness of concrete columns wrapped with CFRP and SFRP sheets. In Proceedings of the Second Conference on Smart Monitoring Assessment and Rehabilitation of Civil Structures (SMAR 2013) Conference, Istanbul, Turkey, 9-11 September 2013; p. 8.

28. Statistic Canada, Government of Canada. Construction Union Wage Rates, Table 327-0003, 2011. Available online: http://www5.statcan.gc.ca/cansim/a26?lang=eng\&retrLang=eng\&id=3270003 \&paSe $\quad \mathrm{r}=\&$ pattern $=\&$ stByVal=1\&p1 $=1 \& \mathrm{p} 2=31 \&$ tabMode $=$ dataTable $\& \operatorname{csid}=\quad($ accessed $\quad$ on 2 October 2013).

29. Abdelrahman, K.; El-Hacha, R. Validation of digital image correlation technique on CFRP and SFRP wrapped cylinders subjected to freeze-thaw environmental exposure. In Proceedings of the 4th International Conference on Durability and Sustainability of Fiber Reinforced Composites for Construction and Rehabilitation (CDCC-4) Conference, Quebec City, Canada, 20-22 July 2011; pp. 275-283.

30. Bisby, L.; Take, W. Strain localisations in FRP confined concrete: New insights. Struct. Build. 2009, 165, 301-309.

31. Bisby, L.; Chen, J.F.; Li, S.Q.; Stratford, T.J.; Crossling, K. Strengthening fire-damaged concrete by confinement with fibre-reinforced polymer wraps. Eng. Struct. 2011, 33, 3381-3391.

32. Barrington, J.; Dickson, D.; Bisby, L.; Stratford, L. Strain development and hoop strain efficiency in FRP confined square columns. Am. Concr. Inst. (ACI) 2011, 255, 1-20.

33. Islam, M.M.; Choudhury, M.S.I.; Abdulla, M.; Amin, A.F.M.S. Confinement effect of fiber reinforced polymer wraps in circular and square concrete columns. In Proceedings of the 4th Annual Paper Meeting and the 1st Civil Engineering Congress, Dhaka, Bangladesh, 22-24 December 2011; pp. 359-362.

34. Fitzwilliam, J.M. Fibre-Reinforced Polymer Wraps for Slenderness Eccentrically-loaded Reinforced Concrete Columns. Master's Thesis, Department of Civil Engineering, Queen's University, Kingston, ON, Canada, 2006.

35. Smith, S.T.; Kim, S.J.; Zhang, H. Behaviour and effectiveness of FRP wraps in confinement of large concrete cylinders. J. Compos. Constr. ASCE 2010, 14, 573-582.

(C) 2014 by the authors; licensee MDPI, Basel, Switzerland. This article is an open access article distributed under the terms and conditions of the Creative Commons Attribution license (http://creativecommons.org/licenses/by/3.0/). 